Thorax (1972), 27, 365.

\title{
Pulmonary hydatid disease
}

\author{
B. T. le ROUX
}

The Thoracic Unit, Wentworth Hospital, and the Department of Surgery, University of Natal

Radiographic evidence is presented in confirmation of the contention that uncomplicated isolated pulmonary hydatid cysts are seldom completely circular and can be confidently recognized as hydatid cysts radiographically and fluoroscopically.

Pulmonary hydatid disease is a particular radiological diagnostic problem when the hydatid is small, single, and symptomless, so that distinction must be made from the numerous other causes of isolated, peripheral pulmonary lesions. The technique of delivery of a pulmonary hydatid cyst, different from the management of other single peripheral lesions, makes preoperative recognition of hydatid disease important. Uncomplicated pulmonary hydatid cysts are seldom completely circular because they are so soft that they are dented and disfigured by adjacent structures-on this peculiarity of shape there is unanimity of opinion; that their outline is blurred in one or more places by areas of pneumonitis, haemorrhage or infarction (Barrett and Thomas, 1944), whose comprehensive paper carries the salutary and appropriate admonition cave canem as sub-title, is questionable - sharp definition, without adjacent pulmonary reaction, is typical of the solitary, small uncomplicated hydatid cyst (Shanks and Kerley, 1962). Close proximity to a pleural surface is common (Brown, 1958) but by no means invariable.

Hydatid disease is endemic in the Natal midlands, that area to the east of the escarpment in the foothills of the Drakensberg mountains. Over a five-year period the diagnosis of isolated pulmonary hydatid cyst has been confirmed in 17 patients. Three were symptomatic-one because of vertebral hydatid disease (Fig. 1) and two because of rupture of the hydatid, into the pleura in one and into the bronchial tree in the other. The remainder were chance findings in patients for
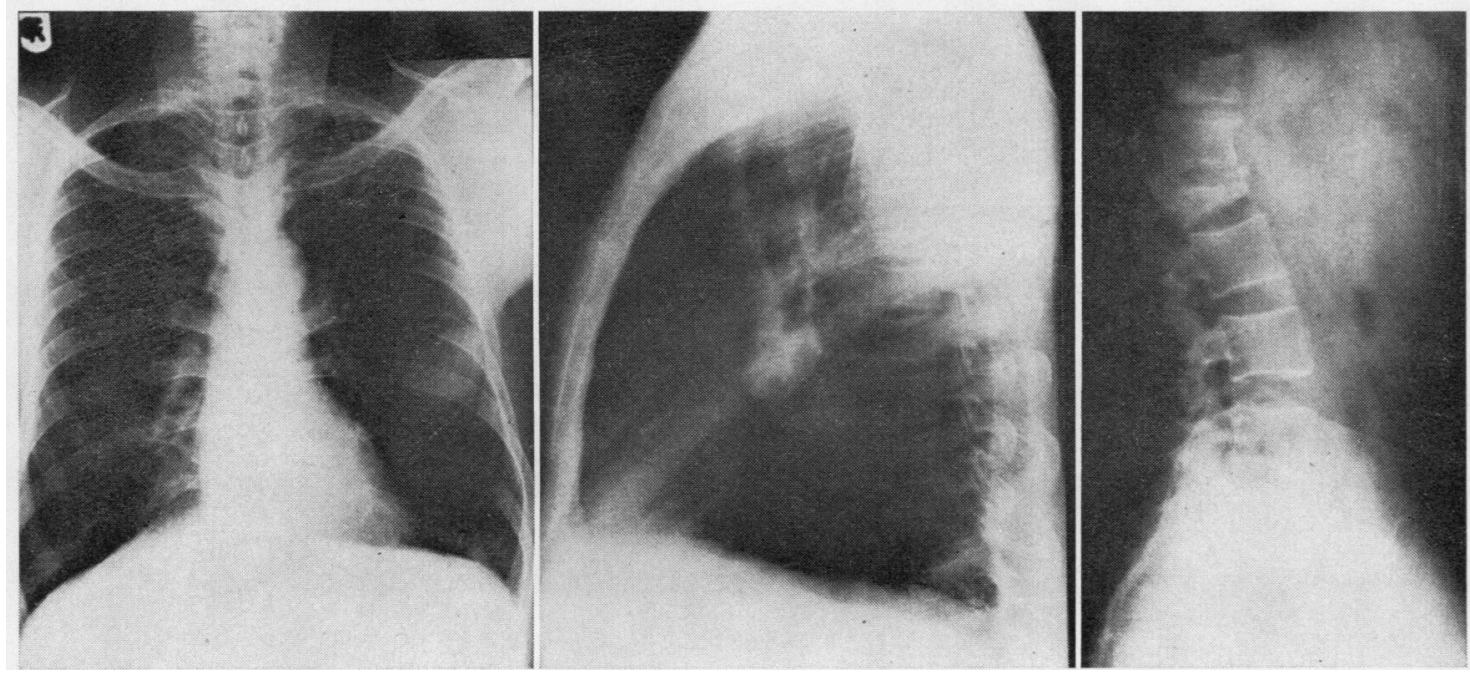

FIG. 1. A left-sided pulmonary hydatid cyst in a patient with vertebral collapse consequent upon infestation with Echinococcus granulosus. 

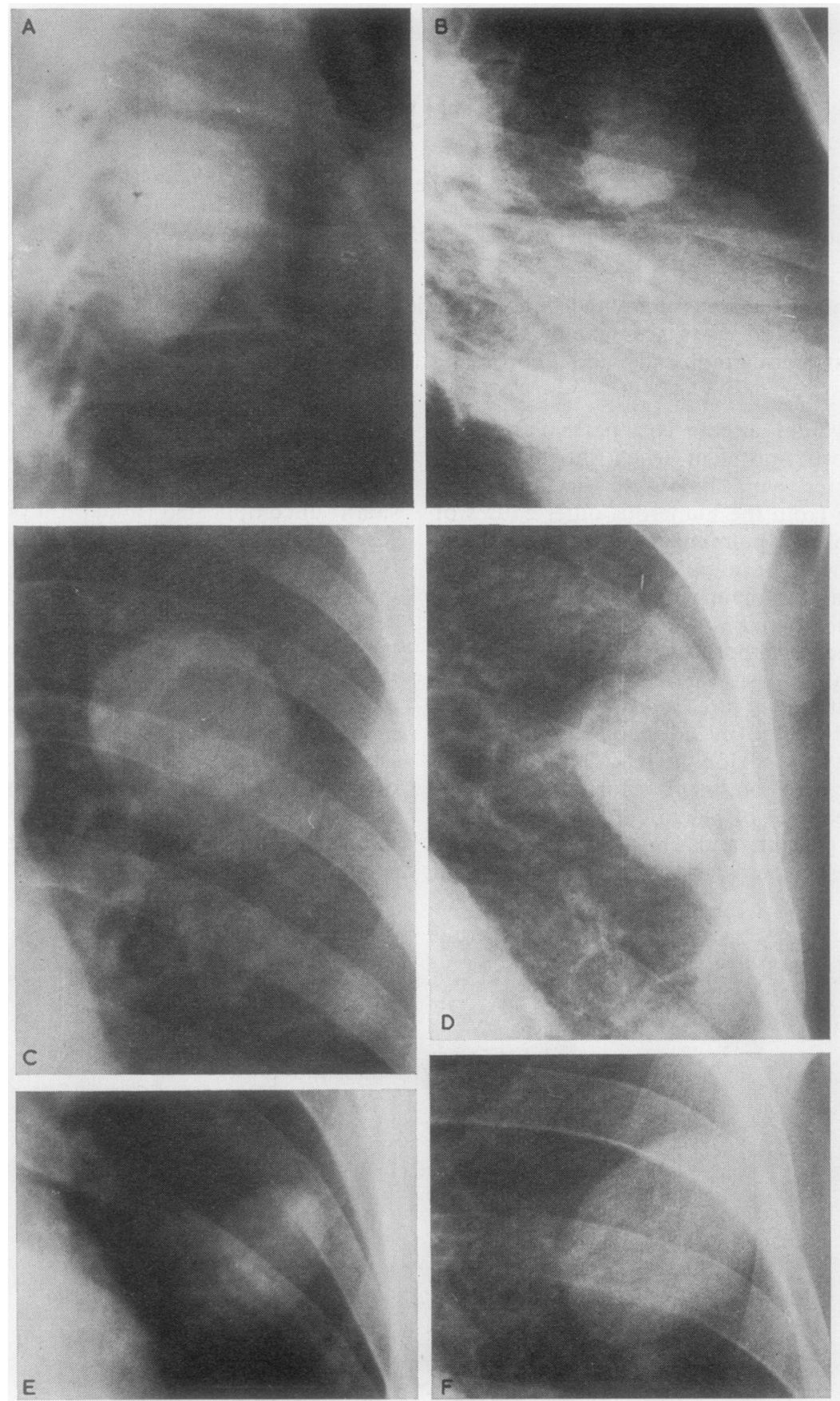

FIG. 2. Six examples of isolated uncomplicated pulmonary hydatid cysts. None is spherical. In four $(A, C, D$, and $E)$ the cyst is clearly folded upon itself. All changed shape considerably with the phases of forced respiration at fluoroscopy. The egg shape of the cyst $(F)$ with small notches, which deform the otherwise smooth and hairline outline, is typical. 
whom chest radiographs were made for routine purposes, and in all, the diagnosis of pulmonary hydatid disease was confidently made on the basis of the dented, often folded, shape of the lesions. None was spherical. Most were the size of a hen's egg. Radiographs of 6 of 14 surgically managed patients are shown (Fig. 2). Confirmatory evidence of the softness of the intrapulmonary lesion was obtained at fluoroscopy, when the cysts were seen to change shape over a wide range during full respiratory excursion.

Management in 14 patients was by incision of the adventitious capsule and delivery of the cyst by inflation of the lungs. Two cysts ruptured during delivery, with contamination of the pleural space. The patients whose pleural spaces were so contaminated have been observed over four years, and neither has evidence of a recurrence of hydatid disease. All 14 patients are well.

During the same period isolated uncomplicated pulmonary hydatid disease was diagnosed on radiographic and fluoroscopic evidence in eight other symptomless patients who declined surgical management. These patients continue to attend for regular surveillance and it is hoped, from them, to obtain radiographic evidence of the natural history of untreated pulmonary hydatid cysts.

\section{REFERENCES}

Barrett, N. R., and Thomas, D. (1944). Pulmonary hydatid disease. Brit. J. Tuberc., 38, 39.

Brown, C. J. Officer (1958). Surgical pathology of hydatid cysts of the lung. Postgrad. med. J., 34, 195.

Shanks, S. C., and Kerley, P. (1962). A Textbook of X-ray Diagnosis, 3rd ed., Vol. 2. Lewis, London. 